\title{
ENSAIO SOBRE A CONSTITUIÇÃO DE UM "PEDAÇO” DA CULTURA LÚDICA INFANTIL NAS CIDADES ${ }^{1}$
}

Recebido em: 07/11/2014

Aceito em: 26/03/2015

Flávia Martinelli Ferreira ${ }^{2}$

Prefeitura de Jundiaí

Jundiaí - SP - Brasil

Jocimar Daolio ${ }^{3}$

Universidade Estadual de Campinas (Unicamp)

Campinas - SP - Brasil

RESUMO: Este ensaio busca a compreensão das brincadeiras infantis realizadas na cidade fundamentadas em considerações sobre a antropologia urbana e a cultura lúdica infantil. Escolhemos as ruas para representar o espaço de troca entre crianças e a cidade. Nas ruas ocorre o encontro de crianças de diferentes origens e experiências. Neste sentido, a rua representa o local onde brincadeiras são formuladas e recriadas, compondo uma rica cultura urbana. O "pedaço" das crianças é o uso que se faz da rua e uma presença criativa de seus usuários nestes espaços. Como tentativa de ilustrar este contato serão descritas duas imagens de brincadeiras infantis realizadas nestes "pedaços" de socialização. Ao longo deste ensaio, pretendemos evidenciar que o "pedaço" das crianças não está delimitado e precisa ser construído e ocupado.

PALAVRAS CHAVE: Jogos e Brinquedos. Cidades. Criança. Atividades de Lazer.

\section{ESSAY ON THE ESTABLISHMENT OF A "PEDAÇO” OF CHILDHOOD PLAY CULTURE IN CITIES}

ABSTRACT: This essay seeks the comprehension of children's play performed in the city based on considerations from urban anthropology and children ludic culture. We chose streets to represent the exchange space between children and city. There occurs the meeting of children belonging from different backgrounds and experiences. Thus, it represents the place where plays are formulated and recreated, composing a rich urban culture. The "pedaço" of children is the use of the street by the creative presence of its users. As attempt to illustrate this contact, two images of children's plays performed in these "pedaço" of socialization will be described. Throughout this essay, we intend to

\footnotetext{
${ }^{1} \mathrm{O}$ presente trabalho não contou com apoio financeiro de nenhuma natureza. A primeira versão deste trabalho foi apresentada no V Congresso Sudeste de Ciências do Esporte na Universidade Federal de Lavras, Lavras, Minas Gerais, 25 a 27 de Setembro de 2014.

2 Professora da Prefeitura de Jundiaí e Mestranda na Faculdade de Educação Física da Universidade Estadual de Campinas.

${ }^{3}$ Professor Titular da Faculdade de Educação Física da Universidade Estadual de Campinas.
} 
prove that the "pedaço" of children are not really defined and actually needs to be built. KEYWORDS: Play and Playthings. Cities. Child. Leisure Activities.

\section{Primeiras Considerações}

Este trabalho é fruto de considerações elaboradas a partir do estudo de autores provenientes da antropologia urbana, analisando suas contribuições para a compreensão das brincadeiras infantis realizadas na cidade e elaboradas a partir das estruturas da cidade. Embora os autores aqui estudados não tenham tomado a infância e as crianças como objetos de investigação centrais em suas obras, nos forneceram diversos subsídios para trabalhar com o tema e com as dimensões fundamentais da infância. Obras de sociólogos clássicos como Georg Simmel são capazes de enriquecer o pensamento sobre a infância na atualidade e os processos de socialização descritos pelo autor serão considerados ao longo deste artigo para discutirmos a cultura lúdica infantil nas cidades (GRIGOROWITSCHS, 2008).

A organização das cidades e de suas estruturas descritas em um primeiro momento estão fundamentadas nos esforços empreendidos por Frugoli $(2005 ; 2006)$ e Magnani (2007; 2012) para destacar suas particularidades e suas deliberações, elaborando novas contribuições sobre antropologia urbana e sobre as produções culturais dos seres humanos nestes espaços.

Magnani (2007) assegura que sem o contato originado pelas cidades, as crianças ficariam restritas ao convívio entre iguais e entre parentes. Em uma análise estrutural ${ }^{4}$

\footnotetext{
4 Neste caso podemos destacar LEVI-STRAUSS $(1971 ; 2003 ; 2012)$ como principal expoente responsável por uma mudança importante na Antropologia a partir da década de 1940 com a corrente do estruturalismo. Para saber mais: LEVI-STRAUSS, Claude. Antropologia Estrutural. 6 ed. Rio de Janeiro: Tempo Brasileiro, 2003; LEVI-STRAUSS, Claude. Pensamento selvagem. 12 ed. São Paulo: Papirus, 2012; LEVI-STRAUSS, Claude. Os limites do conceito de estrutura em etnologia. In: BASTIDE, R. (Org.) Usos e sentidos do termo " estrutura" nas Ciências Humanas e Sociais. São Paulo: Herder, Editora da Universidade de São Paulo, 1971.
} 
sobre as formas de assentamento utilizadas pelos seres humanos ao longo do tempo, os acampamentos estabelecidos por caçadores e coletores - diferentemente do assentamento que constitui as cidades - são definidos como um modo de vida com mobilidade, suas práticas são caracterizadas pelo nomadismo e são destacadas marcas de dispersão ao longo do território.

Em contrapartida, a cidade como a forma de assentamento desenvolvida em um período mais recente, possui tanto estas características de mobilidade quanto características de fixação. Tomando as cidades como objeto de estudo e análise discutimos este encontro das crianças com as cidades, considerando a socialização condicionada por espaços públicos típicos das cidades, como a rua, incluindo suas regras de convivência e práticas culturais.

Ao elaborarmos uma discussão teórica sobre a cidade, amparados nos autores destacados anteriormente, investiremos nos desdobramentos possíveis que emergem das estruturas fundantes que organizam as cidades. Pretendemos desta forma acionar o legado da antropologia sobre as cidades e a cultura urbana para encontrarmos novas perspectivas e categorias de análise para o estudo da cultura lúdica infantil.

Neste ímpeto, o espaço de troca entre as crianças escolhido para representar a cidade será a rua. Nas ruas ocorrem, com frequência, o encontro de crianças com diferentes origens e experiências. Nas ruas também são formuladas e recriadas brincadeiras pelas crianças, compondo a partir desta troca entre diferentes uma rica cultura urbana.

As brincadeiras tradicionais infantis expressam uma produção cultural datada, são transmitidas e estão em constante transformação. Possuem a função de perpetuar as culturas infantis e desenvolver formas de convivência social na cidade. Para Kishimoto (1999), devemos considerar a criança como um ser que brinca e, por isso, considerá-las 
interligadas às suas brincadeiras. Portadora de especificidades que se expressam por meio do brincar, "a infância carrega consigo as brincadeiras que se perpetuam e se renovam a cada geração" (p.11). Em diferentes contextos sociais são criadas diferentes concepções de infância, sua educação e formas de brincar. Este argumento está demonstrado pela autora com exemplos retirados dos diários de Jean Héroard por Ariès (1981).

As brincadeiras descritas remetem aos séculos XIII e XVIII e são, em parte, diferentes daquelas que presenciamos atualmente, tanto em relação à escolha das brincadeiras e brinquedos, como em relação a quem brincava e seus trajes. Os brinquedos usados por Luís XIII compreendiam cavalos-de-pau, cata-ventos e peões. Nesta época, as brincadeiras estavam restritas à primeira infância e desapareciam depois dos três ou quatro anos de idade. Luís XIII também brincava com bonecas porque não haviam distinções entre as brincadeiras dos meninos ou das meninas. Já no século XVIII as distinções também não existiam entre as brincadeiras dos adultos e das crianças: homens, mulheres e crianças brincavam de cabra-cega, jogos de salão e faziam guerras com bolas de neve (ARIÈS, 1981).

As diferentes possibilidades de apropriação dos distintos espaços públicos e produções culturais infantis exemplificados indicam que as características dos lugares em que são realizadas podem influenciar tanto na escolha quanto na construção e reconstrução das brincadeiras. O esforço empreendido neste artigo não será então de refletir sobre uma suposta diminuição das brincadeiras infantis realizadas em espaços públicos como a rua e a ocupação destes espaços pelas crianças; dedicamo-nos ao estudo de autores da antropologia urbana para destacar sua importância na construção de espaços urbanos que sejam locais fundamentais para o exercício do brincar entre as crianças. 
Evidentemente, não são as estruturas fundantes da cidade as únicas variáveis que determinam o fenômeno das brincadeiras urbanas, mas são as ruas e as brincadeiras infantis realizadas nos espaços públicos e privados da cidade que tomaremos como objeto de análise. As mudanças urbanas contemporâneas produzem novas formas de interação e novos produtos culturais compreendidos e criados também pelas crianças. É possível observarmos estas mudanças urbanas tanto na elaboração das brincadeiras infantis quanto nos espaços que são destinados a estas práticas. As diferenças incorporadas nas brincadeiras infantis que serão examinadas neste artigo, realizadas em diferentes épocas e situações são capazes de elucidar este argumento.

Influenciado pelas contribuições teóricas da Escola de Chicago, que será discutida a seguir, Fernandes (2004) nos fornecerá a primeira imagem a ser trabalhada no texto. Tomaremos como imagem uma das inúmeras brincadeiras descritas pelo autor, fruto de um levantamento sobre o folclore paulistano realizado em 1941 e publicado posteriormente. A segunda imagem ${ }^{5}$ tomada como ilustração é uma brincadeira que pode ser realizada de duas formas diferentes nos tempos atuais, em diferentes espaços, de modo que a partir destas descrições poderemos mobilizar os conceitos apresentados anteriormente e defender que a cidade que seja também um espaço público de socialização entre as crianças.

\section{As Contribuições da Antropologia Urbana}

Para discutir a questão da urbanidade na antropologia autores como Frugoli (2005) abordam três momentos específicos em torno desta dimensão. Em um primeiro momento discute-se sobre as décadas iniciais de 1920 e 1930 e a abordagem da Escola

\footnotetext{
${ }^{5}$ A segunda imagem descrita neste trabalho é fruto da experiência docente dos autores, que estiveram em contato com formas possíveis de realização desta brincadeira durante as aulas de educação física.
} 
de Chicago, época em que se definiu uma pauta de pesquisas etnográficas sobre a cidade. A chamada Escola de Chicago, segundo o autor, foi a primeira a tomar a cidade como um laboratório privilegiado para a análise de mudanças sociais.

Em linhas gerais, a noção de cultura urbana formulada pela Escola de Chicago está relacionada principalmente a três autores ${ }^{6}$ : Park (1925), Becker (1996) e Redfield (1949). Estes autores por sua vez se inspiraram em clássicos como Durkheim, Weber, Tönnies e Simmel, que por caminhos distintos buscavam compreender as especificidades das sociedades modernas.

A Escola de Chicago prosseguiu com uma prática pioneira de pesquisas etnográficas, demonstrando em alguns estudos haver certa organização/ordenação internas nos locais estudados. Com isso, reafirmou-se a diversidade constitutiva dos contextos urbanos. Ao diferenciar diversidade e desorganização em um segundo momento, nas décadas de 1970 e 1980 a antropologia urbana buscou uma interface com a sociologia sinalizando sua importância em tais investigações etnográficas e abrindo espaço a outros campos de pesquisa e reflexão. Em um terceiro momento, o autor destaca em seu livro as mudanças urbanas contemporâneas que produziram novos desafios neste campo de investigação.

Em um panorama de intensas mudanças nos planos urbanísticos, ao estudar os modos de vida nestas metrópoles industriais, Simmel $(1967 ; 1983)$ assinalou a presença de um anonimato e de uma impessoalidade nas relações sociais tidas nestes espaços. Isto ocorreu devido ao contato entre os estranhos presentes nos espaços públicos das cidades ser marcado não só pela proximidade física como também pela distância social,

\footnotetext{
${ }^{6}$ Para saber mais sobre os autores consultar: REDFIELD, Robert. Civilização e cultura de folk. São Paulo: Martins, 1949; PARK, Robert E. The city: Suggestions for the Investigation of Human Behavior in the Urban Environment. In: PARK, Robert E; BURGESS, Ernest W. The City. Chicago: University of Chicago, 1925, pp. 1-46; BECKER, H. Conferência: A Escola de Chicago. Mana - Estudos de Antropologia Social, vol. 2, Rio de Janeiro, 1996.
} 
constituindo uma ambiguidade que ocasiona a criação de estilos de vida marcados por uma personalidade blasé. As características marcantes desta personalidade blasé são descritas pelo autor como atitudes de reserva perante o mundo e formas lúdicas e recíprocas de interação.

Além disso, pautado na ideia de que a sociedade constitui-se da interação entre os indivíduos, Simmel (1967) buscou desvendar também como a personalidade se ajustava às forças externas, como as cidades e suas peculiaridades. Segundo o autor, a metrópole criava certas condições psicológicas nos indivíduos que a habitavam. A criança metropolitana, diferente de outros contextos, também demonstra esta característica individualizante se comparada a crianças de meios mais tranquilos. As metrópoles são assinaladas, portanto, por suas características individualizantes e independentes.

Entretanto, existem formas de interação entre os seres humanos que não estão subordinadas ao contexto ou ao propósito pelo qual são originadas. Sendo assim, a autonomia individual passou a ser considerada pelo autor como um valor cultural, possibilitando o surgimento do conceito de socialização, conceito este desenvolvido pelo autor como qualquer forma de interação entre seres humanos.

Portanto, socializar-se implica sempre em transformações, porque aborda processos que são móveis e dinâmicos, não fixos; são transformações tanto estruturais como processuais e individuais. Para conhecermos o papel ativo das crianças é preciso considerá-las como atores sociais e produtores de cultura, repensando o próprio conceito de socialização descrito pelo autor (GRIGOROWITSCHS, 2008).

Devemos considerar que há uma especificidade nos processos de socialização na infância, porque as crianças participam de uma série de interações que acontecem somente neste período que variam cultural e historicamente (GRIGOROWITSCHS, 
2008). Os espaços públicos ou privados, destinados às interações na infância, também variam ao longo da história e das culturas nas quais estão envolvidas as crianças. Os espaços públicos, como as ruas, possuem destaque como lugares privilegiados para interação entre os pares, espaço este em que jogar e brincar revelam-se como ações de fundamental importância.

Partindo de outra análise sobre as cidades, considerando as relações estabelecidas na metrópole a partir de seus centros, temos a revitalização urbana como elemento detentor de grande responsabilidade pelo surgimento de subcentros e contextos multipolares (FRUGOLI, 2006). O autor aponta o caráter excludente destas configurações na cidade e explica que o processo de descentralização das sociedades capitalistas, desde o século XIX, vem sendo substituído por uma dinâmica que é ao mesmo tempo descentralizadora e recentralizadora.

Embora mais fragmentada e dispersa se comparada à cidade de São Paulo, temos como referência a cidade de Los Angeles para compreender também as mudanças urbanas contemporâneas que acontecem na cidade de São Paulo. Segundo Frugoli (2006), o fato de tomarmos a cidade de Los Angeles como referência para a análise da cidade de São Paulo é possível porque ambas apresentam um padrão descentralizado de urbanização. Durante um longo período, os estudos feitos em São Paulo aconteciam nas periferias e não tinham como foco de análise áreas mais centrais da cidade. $\mathrm{O}$ autor analisa e reconstitui como essa centralidade vem sendo redefinida, articulada e negociada pelos grupos sociais dominantes no período mais recente da vida urbana em São Paulo.

Quando nos referimos às crianças, temos as configurações das cidades desde o início e compreendendo as modificações mais atuais, incidindo sobre suas práticas de interação e suas práticas culturais. Outros grupos sociais compostos por adultos, à 
margem dos espaços sugeridos e permitidos pela cidade, no entanto, têm conseguido criar e ocupar novos espaços da cidade e transformá-la em um lugar habitável. Como exemplo temos grupos de skatistas em praças públicas que, embora constantemente expulsos destes locais, ocupam estes espaços para a realização de suas práticas corporais (MACHADO, 2014).

Com o contexto urbano em pauta, devemos considerar dois fatores para sua análise: a paisagem e os atores sociais. A paisagem é entendida por Magnani (2012) como um conjunto de espaços e equipamentos urbanos, constituindo-se como o resultado das práticas e intervenções realizadas pelos atores sociais nestes espaços. Neste sentido, a paisagem urbana não deve ser reduzida somente a um cenário para estas práticas e sua análise não deve se limitar a observação de indivíduos nos espaços das grandes cidades contemporâneas.

Diferentes categorias surgiram a partir dos estudos de antropologia urbana realizados por Magnani (2012) com o intuito de apresentar algumas possibilidades para a compreensão da dinâmica cultural e das sociabilidades presentes nas cidades. A categoria "pedaço" descrita pelo autor evoca laços de pertencimento e estabelece algumas fronteiras que auxiliaram na compreensão de espaços públicos como a rua e de outros espaços privados que forjam a presença das ruas, nos permitindo elaborar algumas reflexões sobre a conquista de um "pedaço" (MAGNANI, 2012) para as crianças nas cidades.

Quando um espaço (ou somente uma parte dele) torna-se referência para delimitar um grupo de frequentadores que possuem uma rede de relações próprias, este espaço é chamado de "pedaço". Este conceito delimita um lugar mediador entre o privado e o público, é o lugar dos chegados. Se antes o espaço privado da casa era ocupado somente pelos parentes, hoje é possível encontrarmos os chegados que 
possuem certa proximidade, ainda que não sejam parte da família e não possuam laços de sangue (MAGNANI, 2012).

Outras categorias analíticas são descritas pelo autor como as manchas que designam espaços de maior consolidação e maior visibilidade nas cidades, os trajetos realizados pelos atores sociais que são fruto de suas escolhas na ocupação das cidades e os circuitos que comportam estes regimes de trocas e encontros na cidade de modo mais amplo, extrapolando até mesmo os próprios limites das cidades.

Embora consideradas como categorias importantes para o estudo e a análise das brincadeiras infantis realizadas nos contextos urbanos, nos debruçamos e entendemos que a categoria "pedaço" descrita por Magnani (2012) é adequada e nos fornece elementos suficientes para subsidiar a análise empreendida neste trabalho. Reiteramos que as categorias analíticas e os conceitos emprestados da antropologia urbana mencionados neste artigo são apontados como uma possibilidade dentre tantas outras para a compreensão das brincadeiras infantis realizadas nos espaços públicos e privados da cidade, contribuindo sobremaneira para a ocupação destes espaços como lugares indispensáveis para produção e transformação das culturas lúdicas infantis.

As mudanças urbanas contemporâneas também são capazes de produzir novas formas de ocupação e novos produtos culturais que são reproduzidos e criados pelas crianças. A seguir descreveremos, a partir das imagens de duas brincadeiras infantis, as estruturas da cidade incidindo sobre as práticas culturais das crianças que atualmente são realizadas tanto na rua quanto em outros espaços públicos ou privados.

\section{As Brincadeiras Infantis: "Calçadinha é Minha" e "Mãe da Rua"}

As brincadeiras são espaços e tempos sociais criados intencionalmente pelas crianças e que exigem regras e convenções que sejam aceitas por todos os envolvidos. 
Assim, as crianças manipulam imagens e símbolos culturalmente criados por determinadas sociedades, fornecendo diferentes sentidos e formas, criando seus próprios significados (BROUGÈRE, 1997). São consideradas, deste modo, como um mundo incerto, que não é controlável; um mundo que traz consigo a imprevisibilidade do risco e do acaso. São capazes de proporcionar às crianças espaços e tempos de invenção e recriação, para experimentarem diversas situações.

Para Brougère (1997) a cultura lúdica é definida em um duplo movimento: interno e externo. As experiências adquiridas por sua participação em brincadeiras realizadas com seus pares e pela observação de outras crianças são os movimentos internos. Isso significa dizer que estas experiências não são simplesmente transferidas, mas que as crianças são também construtoras de sua cultura lúdica. Dizer que elas são também objeto de produção externa garante de tal modo consentir que essa experiência se alimentasse de elementos culturais vindos do exterior, como o ambiente e as condições materiais (BROUGÈRE, 2011). Deste modo, consideramos que alguns elementos parecem ter uma incidência especial sobre as culturas infantis, como defendemos ser o caso da cidade, da rua e de seus espaços públicos e privados.

Os primeiros subsídios para compreensão da infância e dos elementos que constituem as culturas infantis são elaborados na década de 1940 e publicados somente no ano de 1961. As "trocinhas" dos bairros paulistanos como Bom Retiro, Lapa, Bela Vista, Brás e Pinheiros, segundo Fernandes (2004), são grupos infantis que possuem linguagens, ritos e estruturas próprias; são constituídas por grupos infantis que se apresentaram organizados e regulamentados, assegurando sua existência por muitos anos mesmo com a ausência de alguns membros.

Ao estudar estes grupos infantis formados nas ruas, o autor afirma que estas "trocinhas" estão condicionadas ao desejo de brincar, embora sua organização 
ultrapasse os limites de tão só uma recreação. Há uma cultura infantil constituída de elementos folclóricos que foram passados aos grupos infantis e são quase exclusivos destes grupos. No entanto, em grande parte estes elementos originam-se no mundo adulto e são incorporados e modificados pelas crianças.

Evidenciamos a partir deste processo de formação da cultura infantil descrito que esta é tanto constituída por elementos aceitos da cultura do adulto quanto por elementos ordenados pelas próprias crianças. Assim sendo, defendemos que não se trata somente da aquisição de alguns elementos culturais, mas sim da aquisição das idéias do mundo adulto e das representações da própria sociedade.

A primeira imagem que nos permitirá refletir sobre os espaços públicos e privados destinados às brincadeiras infantis e sobre as estruturas fundantes das cidades que influenciam tanto a construção da brincadeira como as maneiras de brincar foi descrita pelo autor da seguinte forma:

\section{Imagem 1}

b) Calçadinha é minha (Bela Vista, Pari e Lapa)

Uma criança "faz de rainha", não deixando as outras subirem na calçada. Quando consegue prender uma delas, na calçada, esta ficará encostada na parede. As outras procuram tirar as companheiras "aprisionadas", sem que a rainha o perceba, e cantam, subindo na calçada:

Calçadinha é minha

Não é da rainha!

Calçadinha é minha

Não é da rainha!

(FERNANDES, 2004, p.57)

A brincadeira citada é usada como uma primeira imagem para ilustrar o debate sobre as estruturas fundantes das cidades e seus cerceamentos de possibilidades do brincar infantil. Levando em conta a descrição da brincadeira, é possível perceber que esta era realizada em uma cidade que permitia às crianças tornar a rua e suas calçadas como "pedaços" (MAGNANI, 2012) de sentidos e significados. 
As crianças, portanto, se dividiam neste espaço, ocupando calçadas e paredes próximas às ruas. Retomando a ideia da rua ocupada como um espaço para socialização das crianças, temos este lugar nos bairros paulistanos da década de 1940, como descrito por Fernandes (2004), sendo um lugar privilegiado de interação entre as crianças e de produção de cultura. Através das experiências vivenciadas a criança selecionava, modificava e criava representações sobre as coisas, a depender do que lhes permitiam vivenciar as cidades. Sendo assim, em movimento temos este contato das crianças com a cidade ilustrado a partir desta brincadeira.

Os espaços destinados à ocupação de grupos como as "trocinhas" de bairros paulistanos (FERNANDES, 2004) permitiam neste sentido produções culturais infantis que incorporassem a cultura do mundo adulto e a transformassem neste espaço que lhes era destinado. Logo, podemos sugerir a incidência determinante dos espaços públicos, como as ruas, sobre a cultura lúdica elaborada pelas crianças.

No entanto, a partir da segunda imagem que será usada para ilustrar a discussão, desta vez nos tempos atuais, temos a descrição de uma brincadeira elaborada de duas formas: com a possibilidade de ser feita ainda na rua ou de ter sua reprodução assegurada em outros espaços. Destacamos deste modo que as cidades consideradas hoje metrópoles, como é o caso da cidade de São Paulo, admitem inúmeras estruturas e formas de serem ocupadas, não admitindo apenas as produções culturais infantis elaboradas em espaços públicos como as ruas.

\section{Imagem 2}

\subsection{Na rua}

As crianças se dividem em dois grupos. Cada grupo fica de um lado (se for em uma rua tranquila, fica um em cada calçada). A criança escolhida como a mãe da rua permanece no espaço que há entre eles. As crianças têm de atravessar de uma calçada a outra para fugir da mãe da rua. Quem é pego ajuda a capturar os demais. O primeiro a ser capturado será a próxima mãe da rua. A brincadeira termina quando a turma toda for pega. 


\subsection{Em outro espaço}

Uma das crianças será escolhida para ser a mãe da rua. Com um giz ou outro material, desenham duas riscas paralelas com uma distância de cerca de dois metros entre elas. O lado de dentro das riscas será a rua e o lado de fora, as calçadas. O objetivo é atravessar para o outro lado sem ser apanhado pela mãe da rua. Quem é pego ajuda a capturar os demais. O primeiro a ser capturado será a próxima mãe da rua. A brincadeira termina quando a turma toda for pega.

As mudanças urbanas que aconteceram ao longo de décadas foram capazes de produzir novas formas de interações criadas pelas crianças e pelos adultos, permitindo que uma brincadeira seja realizada de duas formas. Atualmente, as crianças que vivem em regiões metropolitanas com a cidade de São Paulo, com ruas largas e tomadas por carros e construções, foram obrigadas a encontrar novos espaços de socialização para realização de brincadeiras, com os parques, condomínios ou as escolas. Quando perdem um espaço na cidade, as crianças elaboram novas formas de realizar as brincadeiras determinadas pelo novo espaço disponível e acabam por construir um novo "pedaço" (MAGNANI, 2012) com novas ruas e calçadas, ainda que estas sejam construídas com traços de giz.

No primeiro formato descrito a partir da segunda imagem, temos a substituição da rainha mencionada na década de 1940 pela mãe, que é a atual dona da rua. No segundo formato, há a substituição do próprio espaço de realização da brincadeira e uma construção nova da maneira de brincar a partir da mudança do ambiente. No entanto, ainda que a rua esteja forjada em um desenho, não perde seu papel que continua evidenciado na construção e elaboração da brincadeira. A rua, antes ocupada como espaço privilegiado de socialização das crianças, é hoje traçada em outros espaços possíveis para que esta socialização aconteça. 
É importante destacar que as considerações elaboradas a partir destas descrições não emergem de um estudo aprofundado das brincadeiras infantis que são realizadas atualmente nos bairros paulistanos, mas apontam para uma possibilidade a partir do estudo destas cidades metropolitanas, considerando as crianças também como seus atores sociais. Os conhecimentos sobre os usos dos espaços públicos pelas crianças podem encorajar, como resultado, algumas mudanças na elaboração de um planejamento urbano.

\section{Por uma "Pedaço" da Cultura Lúdica Infantil nas Cidades}

Ao longo do trabalho, a rua foi escolhida como espaço legítimo para representar a cidade e ilustrar o debate com as brincadeiras infantis que nela são realizadas. A trajetória adotada contou inicialmente com a discussão de autores da antropologia urbana para nos posicionar no debate sobre as estruturas fundantes das cidades e suas peculiaridades. Diante do exposto consideramos as crianças como atores sociais envolvidos nos processos de construção e ocupação das cidades, refletindo sobre suas brincadeiras descritas na década de 1940 e nos tempos atuais como imagens para ilustrar nosso argumento.

Com suas características distintas de mobilidade e de fixação, a cidade é capaz de promover o encontro de crianças com diferentes experiências e formular, a partir disto, novas possibilidades de criar e recriar brincadeiras, elaborando uma rica cultura urbana. Como já destacado ao longo do texto, sem este contato originado pelas cidades, as crianças estariam restritas a um convívio entre parentes e iguais. As brincadeiras infantis descritas demonstram a existência de uma cultura lúdica presente nas cidades, que são modificadas a partir das mudanças nas estruturas fundantes deste espaço. 
Consideramos que as brincadeiras infantis aqui descritas buscaram ilustrar o eixo de argumentação desenvolvido durante o trabalho, em busca de uma abordagem que se refere a uma antropologia da cidade; em outro sentido, a descrição de brincadeiras realizadas na cidade sem as contribuições apresentadas pela antropologia urbana estariam sujeitas somente a um relato de fenômenos que ocorrem nestes espaços.

No entanto, as brincadeiras infantis descritas nos "pedaços" (MAGNANI, 2012) de socialização das crianças foram tentativas de ilustrar seu contato com as cidades, que são espaços excepcionais para este exercício de sua sociabilidade. No caso das crianças, devemos iniciar desde cedo, no exercício da cidadania, este contato com outro ambiente e outras pessoas. Desde cedo, as crianças devem encontrar-se com novas regras, internalizadas neste ambiente lúdico, para que sejam capazes de aprender, compartilhar e negociar (MAGNANI, 2007).

Os espaços públicos e privados ocupados com manifestações culturais de lazer nas cidades devem ser dispositivos que propiciem às crianças a elaboração de uma cultura lúdica rica, envolvendo suas constantes transformações e ponderando sobre as diferentes estruturas encontradas nas cidades atualmente.

As organizações formais representadas por clubes, academias ou escolas e as organizações informais compostas por grupos de amigos, grupos de conhecidos ou desconhecidos e pelas "trocinhas" formadas pelos grupos infantis incitam diferentes modos de construção das práticas corporais de lazer. Do mesmo modo González (2007) adverte que os espaços nos quais são realizadas estas ações (públicos ou privados) condicionam essas possibilidades dos seres humanos socializarem-se e estas formas de organização configuram-se na maneira pela qual os grupos presentes nestes espaços se relacionam, construindo suas sociabilidades. Diante destas considerações, o autor 
defende que devemos levar em consideração a tensão entre uma autonomia relativa destes sujeitos e as condicionantes da vida social.

Assim como demonstrado pelo autor, referindo-se às práticas esportivas de lazer na cidade, pretendemos ao longo deste trabalho evidenciar que o "pedaço" de socialização da cultura lúdica infantil não está dado e precisa ser construído e ocupado. Sem direcionar as crianças a um espaço fechado e isolado, restrito em suas possibilidades, precisamos tornar a rua um espaço de convivência mais estimulante e acolhedor. Este pedaço das crianças, não previsto no planejamento urbano, é na verdade um uso que se faz da rua e uma presença criativa de seus usuários, que precisa ser conquistado por todos (MAGNANI, 2007).

Para tanto, é necessário retomar o argumento que propõe uma cultura lúdica infantil adquirida tanto pela participação das crianças nas brincadeiras quanto pela observação de outras crianças, retomando a ideia proposta por Brougère (1997) de que estas experiências não são apenas transferidas, mas que as crianças participam igualmente da construção e da transformação desta cultura lúdica. Com as contribuições apresentadas pelas categorias analíticas da antropologia urbana é possível afirmar que a cultura lúdica infantil está condicionada também por elementos culturais exteriores, como as cidades e seus espaços.

\section{REFERÊNCIAS}

ARIÈS, P. História social da criança e da família. Trad. Dora Flaksman. 2. ed. Rio de Janeiro: Zahar Editores, 1981.

BECKER, H. Conferência: A Escola de Chicago. Mana - Estudos de Antropologia Social, v. 2, Rio de Janeiro, 1996.

BROUGÈRE, G. Brinquedo e cultura. 2. ed. São Paulo: Cortez, 1997. 
BROUGÈRE, G. A criança e a cultura lúdica. In: O brincar e suas teorias. KISHIMOTO, T. M. (Org.). São Paulo: Cengage Learning, 2011.

FERNANDES, F. Folclore e mudança social na cidade de São Paulo. 3. ed. São Paulo: Martins Fontes, 2004.

FRUGOLI JR, H. O urbano em questão na antropologia: interfaces com a sociologia. Revista de Antropologia, São Paulo, USP, 2005, v. 48, n.1.

Centralidade em São Paulo: trajetórias, conflitos e negociações na metrópole. São Paulo: Cortez, Edusp, 2006.

GONZÁLEZ, F. J. Sociabilidades e práticas corporais: leitura de uma relação. In: STIGGER, M. P. (Org.); GONZÁLEZ, F. J. (Org.); SILVEIRA, R. (Org.) O Esporte na Cidade - Estudos Etnográficos sobre Sociabilidades Esportivas em Espaços Urbanos. Porto Alegre: Editora da UFRGS, 2007.

GRIGOROWITSCHS, T. O conceito "socialização" caiu em desuso? Uma análise dos processos de socialização na infância com base em Georg Simmel e George H. Mead. Revista Educação e Sociedade, v. 29, n.102, p. 33-54, jan-abr, 2008.

KISHIMOTO, T. M. Jogos infantis: o jogo, a criança e a educação. 6. ed. Petrópolis: Vozes, 1999.

LEVI-STRAUSS, Claude. Antropologia Estrutural. 6. ed. Rio de Janeiro: Tempo Brasileiro, 2003.

LEVI-STRAUSS, Claude. Pensamento selvagem. 12. ed. São Paulo: Papirus, 2012;

LEVI-STRAUSS, Claude. Os limites do conceito de estrutura em etnologia. In: BASTIDE, R. (Org.) Usos e sentidos do termo "estrutura" nas Ciências Humanas e Sociais. São Paulo: Herder, Editora da Universidade de São Paulo, 1971.

MACHADO, G. M. C. Praça Roosevelt: sociabilidade e conflitos em um pedaço skatista da cidade de São Paulo. Revista Perifèria, n. 19, p. 82-107, junho, 2014.

MAGNANI, J. G. C. Quando o campo é a cidade: fazendo antropologia na metrópole. In: MAGNANI, J. G. C; TORRES, L. (Org.) Na metrópole. São Paulo: Editora USP, 1996. jan.2007.

O pedaço das crianças. In: Revista SESC SP, São Paulo, p. 40 - 41, 01

Da periferia ao centro: trajetórias de pesquisa em antropologia urbana. São Paulo: Editora Terceiro Nome, 2012.

PARK, Robert E. The city: Suggestions for the Investigation of Human Behavior in the Urban Environment. In: PARK, Robert E; BURGESS, Ernest W. The City. Chicago: University of Chicago, 1925, p. 1-46

REDFIELD, Robert. Civilização e cultura de folk. São Paulo: Martins, 1949. 
SIMMEL, G. A metrópole e a vida mental. In: VELHO, Otávio G. (Org.) O fenômeno urbano. Rio de Janeiro: Zahar Editores, 1967.

Sociabilidade - um exemplo de sociologia pura ou formal. In: MORAES, E. (Org.), Sociologia: Simmel, São Paulo, Ática, p. 165-181.

\section{Endereço dos Autores:}

Flávia Martinelli Ferreira

Rua Luís Dionísio de Souza, n. 375, ap. 64, torre 4

Bairro Jardim Miriam

Campinas - SP - 13098-426

Endereço Eletrônico: flaviamartinelli@uol.com.br

Jocimar Daolio

Faculdade de Educação Física - FEF

Avenida Érico Veríssimo, 701

Cidade Universitária Zeferino Vaz - Barão Geraldo

Campinas - SP - 13.083-851

Endereço Eletrônico: jocimar@fef.unicamp.br 